\title{
PENERAPAN METODE WP PENENTUAN PENYIDIK TERBAIK DI SAT NARKOBA POLRES DELI SERDANG
}

\author{
Murni Marbun ${ }^{1}$, Maliki Ginting ${ }^{2}$, Bambang Krismoyo ${ }^{3}$ \\ 1,2,3Program Studi Teknik Imnformatika, STMIK Pelita Nusantara Medan \\ e-mail: ${ }^{1}$ dimpeflorence@yahoo.co.id , 2Malikiginting6017@gmail.com, \\ 3krismoyobambang@gmail.com
}

\begin{abstract}
Abstrak
Penentuan penyidik terbaik membutuhkan suatu metode yang tepat agar tidak terjadi kecurangan yang akan menimbulkan ketidakadilan bagi penyidik-penyidik yang lain di SAT Narkoba Polres Deli Serdang. Metode Weighted Product merupakan metode yang efektif karena waktu yang dibutuhkan untuk perhitungan jauh lebih singkat. Metode Weighted Product mengunakan perkalian untuk menghubungkan rating atribut, di mana rating setiap atribut harus dipangkatkan terlebih dahulu dengan bobot atribut yang bersangkutan. Proses ini sama halnya dengan proses normalisasi.Weighted Product merupakan keputusan analisis multi kriteria yang popular dan merupakan metode pengambilan keputusan multi kriteria. Kriteria penentuan penyidik terbaik di SAT Narkoba Polres Deli Serdang terdiri dari attitude/sopan santun, kinerja, absensi dan masa kerja. Tujuan dari penelitian ini adalah menerapkan metode Metode Weighted Product untuk memilih penyidik terbaik di SAT Narkoba Polres Deli Serdang. Berdasarkan kriteria yang telah ditentukan dari 5 orang sampel Penyidik yang ada di SAT Narkoba Polres Deli Serdang, hasil penerapan metode Weighted Product mendapatkan hasil dalam bentuk peringkat, yaitu peringkat 1 sampai 5. Penerapan metode Weighted Product memberikan rekomendasi peringkat sebagai penyidik terbaik yaitu $E$. Lumbantoruan dengan nilai $V_{1}=0.24$
\end{abstract}

Keywords: WP, Penyidik Terbaik, Narkoba

\begin{abstract}
Determination of the best investigators is needed on the right method to avoid fraud that will cause injustice to other investigators at the Police Narcotics SAT, Deli Serdang. The Weighted Product Method is an effective method because the time required for calculations is much shorter. The Weighted Product method uses the rating attribute to be transferred, where the rating of each attribute must be raised first by adding the required attributes. This process is the same as the normalization process. The insightful product is a popular multi-criteria analysis and is a multicriteria decision making method. The criteria for selecting the best investigators in the Police Narcotics SAT, Deli Serdang consists of attitude/manners, performance, presence and years of work. The purpose of this study is the application of the Weighted Product method to select the best investigators in the Police Narcotics SAT, Deli Serdang. Based on predetermined criteria from 5 Investigation samples in the Police Narcotics SAT, Deli Serdang, the results of the application of the Weighted Product method get results in rankings, namely ranks 1 to 5 . The application of the Weighted Product method provides an assessment according to the best investigators namely $E$. Lumbantoruan with a value of $V_{1}=0.24$.
\end{abstract}

Keywords: WP, The Best Investigator, Narcotics

1. Pendahuluan

Penyidik Sat Narkoba di Polres Deli

Serdang memberikan penghargaan kepada penyidik terbaik setiap tahun untuk memberikan motivasi kepada penyidik agar dapat melakukan tugasnya dengan penuh tanggungjawab. Dalam menentukan penyidik terbaik yang akan mendapatkan penghargaan tersebut, bukan hanya berdasarkan kenyataan di lapangan saja tapi berdasarkan kriteria - kriteria lainnya. Polres Deli Serdang selama ini masih melakukan pemilihan berdasarkan keadaan dilapangan dan tidak jarang pula keputusan ini diambil kurang tepat, sehingga 
menimbulkan perdebatan di antara banyak orang dan pihak yang bersangkutan.

Penentuan penyidik terbaik membutuhkan suatu metode yang tepat agar tidak terjadi kecurangan yang akan menimbulkan ketidakadilan bagi penyidikpenyidik yang lain. Menurut Mecleod $\mathrm{R}$ (2012) pengambilan keputusan (decision making) merupakan suatu tindakan untuk memilih diantara berbagai alternatif solusi untuk memecahkan masalah. Keputusan (decision) didefinisikan sebagai tindakan pilihan dan sering kali harus dilakukan untuk mengambil banyak keputusan dalam rangka sebuah proses pemecahan satu masalah (Herdiansah, 2019). Informasi dalam bentuk dashboard akan mempermudah proses pengambilan keputusan, perencanaan terpadu, terstruktur, dan transparan (Carli, 2015).

Menurut Apriliani, D., Wiyono, S., \& Mahardhika, S. (2018) salah satu metode yang digunakan dalam pemberian penilaian maupun proses seleksi untuk menentukan alternative terbaik dari sejumlah alternative yang ada adalah Fuzzy-MADM. Salah satu metode yang ada dalam algoritma FuzzyMADM yaitu metode Weighted Product atau yang biasa dikenal dengan istilah WP. WP adalah keputusan analisis multi-Kriteria yang populer dan merupakan metode pengambilan keputusan multi-kriteria (Engineering, I., Lingga, D. M., Marbun, M., \& Informatika, T. 2019).

Penelitian yang telah menerapkan metode WP sudah banyak dilakukan. Series, C. (2019) mendesain sistem pendukung keputusan untuk menentukan gula merah berkualitas dengan merapkan metode WP. Metode ini dipilih karena masalah dalam penelitian ini adalah masalah peringkat. Metode WP mampu memilih alternatif terbaik dari sejumlah alternatif dan keunggulannya dalam pembobotan teknik. Metode WP dapat memberi peringkat gula merah dengan menghitung bobot kriteria. Berat nilai dicari untuk setiap atribut, kemudian melakukan proses pemeringkatan untuk menentukan yang alternatif optimal, yang merupakan gula merah terbaik dan layak dalam hal peringkat.

Supriyono, H., \& Sari, C. P. (2018) membahas pengembangan sistem pendukung keputusan pemilihan rumah menggunakan metode WP. Makalah ini menyajikan karya empiris dari pengembangan dukungan keputusan sistem untuk pemilihan rumah. Ada sebelas kriteria utama yang terlibat dalam pemilihan rumah ini dan hasil perhitungan menunjukkan bahwa metode WP mampu memberikan peringkat setiap alternatif untuk membantu pengambil keputusan dalam memilih alternatif terbaik.

Berdasarkan penelitian yang telah menerapkan metode WP, maka Metode MADM yang telah diusulkan pada penelitian ini adalah Weighted Product (WP). Metode ini lebih efisien daripada metode lain dalam pemecahan masalah MADM. Alasannya karena waktu yang dibutuhkan dalam perhitungan. Metode ini berdiri dengan perhitungan sederhana, dan mudah diterapkan dalam kasus yang memiliki elemen subjektivitas tinggi, efektif untuk mengoptimalkan masalah keputusan (Profile, 2018).

\section{Teori Metode Weighted Product}

Metode WP adalah metode penyelesaian yang ditawarkan untuk menyelesaikan masalah Multi Attribute Decision Making (MADM) dan mirip dengan metode Meighted Sum (WS), tetapi metode WP berisi perkalian dalam perhitungan matematika. Metode ini disebut juga analisis dan tidak melakukan proses normalisasi data. Di bawah ini adalah langkah-langkah untuk menganalisis metode WP (Engineering, I., Lingga, D. M., Marbun, M., \& Informatika, T. 2019):

1. Menentukan kriteria-Kriteria yang akan dijadikan acuan dalam pengambilan keputusan yaitu Ci (Setiadi A, 2018).

2. Menentukan bobot awal untuk masing kriteria yaitu:

$$
\mathrm{W}_{\mathrm{j}}=\frac{W j}{\sum w j}
$$

$\mathrm{W}_{\mathrm{j}}$ merupakan $\mathrm{W}$ index ke j. Dan $\sum w j$ merupakan jumlah dari bobot.

3. Menentukan vektor S

Nilai vektor $S$ diperoleh dengan cara mengalikan data setiap nilai alternatif rating kecocokan yang berpangkat positif dari hasil perbaikan bobot (Aini, N, 2017). Hasil perhitungan nilai vektor Si dari setiap alternatif dapat dilihat seperti berikut;

$$
s_{i}=\prod_{j=1}^{n} x_{i j}^{w_{i j}}
$$

dimana : 

S : Preferensi alternatif dianologikan
sebagai vektor $S$

$X$ : Nilai kriteria

W : Bobot kriteria/subkriteria

i : Alternatif

j : Kriteria

n : Banyaknya kriteria

3. Menentukan vektor $\mathrm{V}$

Hasil perhitugan Vektor $V$ yang akan digunakan sebagai dasar acuan untuk mendapatkan perangkingan.

$v_{i}=\frac{\prod_{j=1}^{n} x_{i j}^{w_{i j}}}{\prod_{j=1}^{n}\left(x_{i j}\right)^{w_{i j}}}$

Nilai $V_{i}$ yang lebih besar mengidentifikasi bahwa alternatif $\mathrm{Ai}$ lebih terpilih (Arianto, E. Y, 2018).

\section{Metode Penelitian}

Metode penelitian adalah langkah langkah (tahapan penelitian) yang dilakukan oleh peneliti dalam rangka untuk mengumpulkan informasi atau data serta melakukan investigasi pada data yang telah didapatkan tersebut. Metode penelitian memberikan gambaran rancangan penelitian yang meliputi antara lain: prosedur dan langkah-langkah yang harus ditempuh, waktu penelitian, sumber data, dan dengan langkah apa data-data tersebut diperoleh dan selanjutnya diolah dan dianalisis. Tahapan penelitian yang dilakukan pada penelitian ini adalah:

1. Menentukan Domain persoalan yaitu menentukan area/wilayah yang akan diteliti. Domain Penelitian ini adalah penerapan metode WP dalam menentukan penyidik terbaik

2. Mendefenisikan masalah dalam penelitian. Rumusan Masalah penelitian adalah sebagai berikut :

a. Bagaimana menerapakan metode WP dalam menentukan penyidik terbaik di Sat Narkoba Polres Deli Serdang?

b. Bagaimana memilih penyidik terbaik yang tepat dengan metode WP?

3. Mengumpulkan data yang relevan dengan penelitian. Pengumpulan data dilakukan dengan cara, observasi, wawancara, studi dokumentasi dan studi kepustakaan.

4. Pengolahan data yang telah dikumpulkan dengan menerapkan metode WP dalam menyelesaikan masalah
5. Menganalisis hasil pengolahan data sesuai dengan tujuan dari penelitian dalam penerapan metode WP

6. Menarik kesimpulan berdasarkan hasil analisis pengolahan data.

Tahapan penelitian dapat dilihat pada gambar 1 berikut:

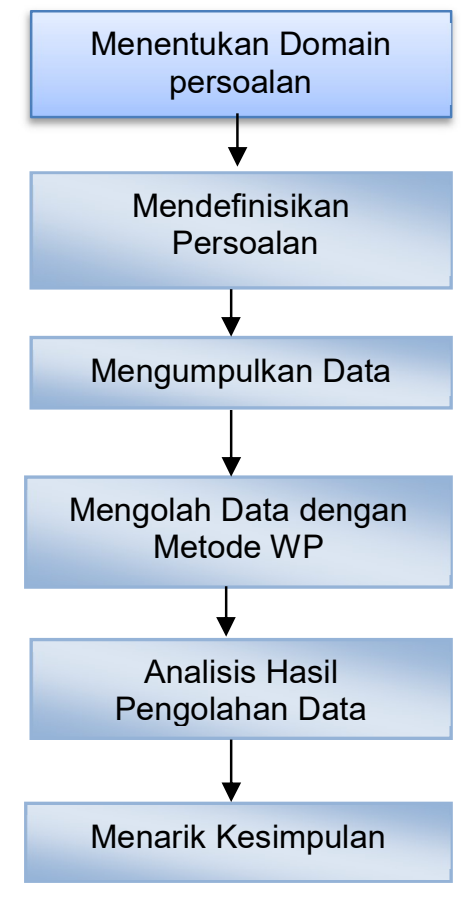

Gambar 1. Tahapan Penelitian

\section{Hasil dan Pembahasan}

\subsection{Hasil Penelitian}

Berdasarkan data dan informasi yang telah diperoleh maka kriteria penyidik terbaik adalah:

a. Attitude (C1)

Berdasarkan ketentuan SAT Narkoba Polres Deli Serdang, attitude penyidik menjadi nilai ukur dalam menentukan penyidik terbaik, nilai persentase attitude paling rendah $50 \%$ yang disahkan oleh bagian SAT Narkoba POLRES Deli Serdang.

Tabel 1. Bobot untuk Kriteria Attitude

\begin{tabular}{|c|c|c|}
\hline Nilai Attitude & Variabel & Bobot \\
\hline $50<$ Attitude $\leq 60$ & Sangat Rendah & 0.20 \\
\hline $61<$ Attitude $\leq 70$ & Rendah & 0.40 \\
\hline $71<$ Attitude $\leq 80$ & Cukup & 0.60 \\
\hline $81<$ Attitude $\leq 90$ & Tinggi & 0.80 \\
\hline $91<$ Attitude $\leq 100$ & Sangat Tinggi & 1.00 \\
\hline
\end{tabular}


b. Kehadiran (C2)

Penyidik wajib datang ke Kantor Polres di SAT Narkoba untuk hadir bekerja tepat waktu. Persentase kehadiran paling rendah sebesar $50 \%$ yang disahkan oleh bagian SAT Narkoba POLRES Deli Serdang.

Tabel 2. Bobot untuk Kriteria Jumlah Kehadiran

\begin{tabular}{|c|c|c|}
\hline Nilai Kehadiran & Variabel & Bobot \\
\hline $50<$ Kehadiran $\leq 60$ & Cukup & 0.60 \\
\hline$>60$ Kehadiran & Tinggi & 0.80 \\
\hline
\end{tabular}

c. Kinerja (C3)

Kinerja adalah adalah hasil kerja secara kualitas dan kuantitas yang dicapai oleh seorang penyidik dalam melaksanakan tugasnya sesuai dengan tanggung jawab yang diberikan kepadanya. Kinerja dalam organisasi, merupakan jawaban dari berhasil atau tidaknya tujuan organisasi yang telah ditetapkan.

Tabel 3. Bobot untuk Kriteria Kinerja

\begin{tabular}{|c|c|c|}
\hline Kinerja & Variabel & Bobot \\
\hline $10<$ Kinerja $\leq 20$ & Sangat Rendah & 0.20 \\
\hline $21<$ Kinerja $\leq 30$ & Rendah & 0.40 \\
\hline $31<$ Kinerja $\leq 40$ & Cukup & 0.60 \\
\hline $41<$ Kinerja $\leq 50$ & Tinggi & 0.80 \\
\hline $51<$ Kinerja $\leq 60$ & Sangat Tinggi & 1.00 \\
\hline
\end{tabular}

d. Masa Kerja (C4)

Masa kerja atau pengalaman seseorang merupakan salah satu persyaratan yang dibutuhkan untuk pengambilan keputusan, berdasarkan masa kerja seseorang tersebut atau pengalamannya dalam bekerja.

Tabel 4. Bobot untuk Kriteria Masa Kerja

\begin{tabular}{|c|c|c|}
\hline Masa Kerja & Variabel & Bobot \\
\hline $1<$ tahun $\leq 2$ & Cukup & 0.20 \\
\hline $4<$ tahun $\leq 5$ & Tinggi & 0.40 \\
\hline$>6$ & Sangat Tinggi & 0.60 \\
\hline
\end{tabular}

\subsection{Pembahasan}

Rating kecocokan dari setiap kriteria adalah mencocokkan bobot yang diberikan dengan data hasil riset. Rating kecocokan dapat dilihat pada tabel 5 berikut:

Tabel 5. Rating Kecocokan

\begin{tabular}{|l|c|c|c|c|}
\hline \multirow{2}{*}{\multicolumn{1}{|c|}{ Alternatif }} & \multicolumn{4}{|c|}{ Bobot Kriteria } \\
\cline { 2 - 5 } & C1 & C2 & C3 & C4 \\
\hline E. Lumbantoruan & 1.00 & 0.80 & 1.00 & 0.60 \\
\hline A.S. Sinulingga & 1.00 & 0.80 & 1.00 & 0.40 \\
\hline P. Situngkir & 1.00 & 0.80 & 1.00 & 0.40 \\
\hline Asrul R Siregar & 1.00 & 0.80 & 0.80 & 0.20 \\
\hline Octa F Sitorus & 1.00 & 0.80 & 0.60 & 0.20 \\
\hline
\end{tabular}

Langkah-langkah Weighted product (WP) sebagai berikut:

1. Normalisasi atau perbaikan bobot

Melakukan perhitungan metode weighted product yang dimulai dengan cara membuat perbaikan bobot kriteria sesuai persamaan 1.

$$
\begin{aligned}
& w_{j}=\frac{w_{j}}{\sum_{j=1}^{n} w_{j}} \\
& w_{1}=\frac{1.00}{1.00+0.80+1.00+0.60}=\frac{1.00}{3.40}=0.29 \\
& w_{2}=\frac{0.80}{1.00+0.80+1.00+0.60}=\frac{0.80}{3.40}=0.24 \\
& w_{3}=\frac{1.00}{1.00+0.80+1.00+0.60}=\frac{1.00}{3.40}=0.29 \\
& w_{4}=\frac{0.60}{1.00+0.80+1.00+0.60}=\frac{1.00}{3.40}=0.18
\end{aligned}
$$

\section{Menentukan nilai vektor S}

$$
\begin{aligned}
& s_{i}=\prod_{j=1}^{n} x_{i j}^{w_{i j}} \\
s_{1}= & \left(1.00^{0.29}\right)\left(1.00^{0.24}\right)\left(1.00^{0.29}\right)\left(1.00^{(0.18)}\right) \\
= & 1.00 \\
s_{2}= & \left(1.00^{0.29}\right)\left(0.80^{0.24}\right)\left(1.00^{0.29}\right)\left(0.40^{(0.18)}\right) \\
= & 0.84 \\
s_{3}= & \left(1.00^{0.29}\right)\left(0.80^{0.24}\right)\left(1.00^{0.29}\right)\left(0.40^{(0.18)}\right) \\
= & 0.84 \\
s_{4}= & \left(1.00^{0.29}\right)\left(0.80^{0.24}\right)\left(0.80^{0.29}\right)\left(0.20^{(0.18)}\right) \\
= & 0.75 \\
s_{5}= & \left(1.00^{0.29}\right)\left(0.80^{0.24}\right)\left(0.60^{0.29}\right)\left(0.20^{(0.18)}\right) \\
= & 0.69
\end{aligned}
$$

3. Menentukan nilai vektor $\mathrm{V}$

Setelah didapat hasil dari pencarian nilai skor, selanjutnya menentukan nilai vektor dari setiap alternatif. Nilai vektor didapatkan dari hasil skor setiap alternatif dibagi seluruh jumlah skor sesuai dengan persamaan. Proses pencarian nilai vektor secara manual sebagai berikut: 


$$
\begin{gathered}
v_{i}=\frac{\prod_{j=1}^{n} x_{i j}^{w_{i j}}}{\prod_{j=1}^{n}\left(x_{i j}\right)^{w_{i j}}} \\
v_{1}=\frac{1.00}{1.00+0.84+0.84+0.75+0.69}=\frac{1.00}{4.12}=0.24 \\
v_{2}=\frac{0.84}{1.00+0.84+0.84+0.75+0.69}=\frac{0.84}{4.12}=0.20 \\
v_{3}=\frac{0.84}{1.00+0.84+0.84+0.75+0.69}=\frac{0.88}{4.05}=0.20 \\
v_{4}=\frac{0.75}{1.00+0.84+0.84+0.75+0.69}=\frac{0.75}{4.12}=0.18 \\
v_{5}=\frac{0.69}{1.00+0.84+0.84+0.75+0.69}=\frac{0.69}{4.12}=0.17
\end{gathered}
$$

\section{Kesimpulan} adalah: Kesimpulan dari penelitian ini

1. Metode WP dapat diterapkan untuk penentuan penyidik terbaik di SAT Narkoba Polres Deli Serdang karena efektif dalam membantu pengambilan keputusan, sehingga tidak ada lagi ketidakadilan dalam pengambilan keputusan penentuan penyidik terbaik

2. Berdasarkan kriteria yang telah ditentukan dari 5 orang sampel penyidik yang ada di Polres Deli Serdang, hasil penerapan metode WP mendapatkan hasil dalam bentuk peringkat, yaitu peringkat 1 sampai 5 . Penerapan WP memberikan rekomendasi peringkat sebagai penyidik terbaik yaitu $E$. Lumbantoruan dengan nilai $\mathrm{V}_{1}=0.24$.

\section{REFERENSI}

Aini, N., \& Agus, F. (2017). Penerapan Metode Weighted Product Dan Analytic Hierarchy Process Untuk Pemilihan Koperasi Berprestasi.

Apriliani, D., Wiyono, S., \& Mahardhika, S. (2018). Penerapan Metode Weighted Product Untuk Sistem Pendukung Keputusan Penerima Beasiswa Politeknik Harapan Bersama Tegal. 03(02), 136-142.

Arianto, E. Y., Siahaan, F. B., \& Informasi, S. (2018). ANALISA PENILAIAN KINERJA KARYAWAN DENGAN METODE FUZZY SIMPLE ADDITIVE WEIGHTING Pada PT. Unilever Indonesia Tbk. 4(1), 194-204.

Engineering, I., Lingga, D. M., Marbun, M., \& Informatika, T. (2019). SISTEM PENDUKUNG KEPUTUSAN MENGGUNAKAN METODE WEIGHTED PRODUCT UNTUK
PENENTUAN PRIORITAS. 3(2), 7985.

Herdiansah, A., Handayani, N., \& Kurniawan, A. (2019). Development of Decision Support Systems Selection of Employee Acceptance Using Weighted Product Method Rancang Bangun Sistem Penunjang Keputusan Penerimaan Penerimaan Karyawan Menggunakan Metode Weighted Product. 1(2), 87-97.

McLeod, R., George, P., Schell., Management Information System, 10th ed. Dialihbahasakan oleh Yulianto, A, Akbar., Afia, R, Fitriati., Jakarta, Salemba Empat, pp.326, 2012

Profile, S. E. E. (2018). Multi-Attribute Decision Making Using Simple Additive Weighting and Weighted Product in Food Choice. (January 2015). https://doi.org/10.5815/ijieeb.2015.06. 02

Series, C. (2019). Decision support system design for determining brown sugar quality with weighted product method Decision support system design for determining brown sugar quality with weighted product method.

Supriyono, H., \& Sari, C. P. (2018). Developing decision support systems using the weighted product method for house selection Developing Decision Support Systems Using the Weighted Product Method for House Selection. 020049(June).

Carli, R., Albino, V., Dotoli, M., Mummolo, G., Savino, M., A Dashboard and Decision Support Tool for The Energy Governance of Smart Cities. Jurnal IEEE, DOI: 10.1109/EEMS. 2015.7175846, Date of Conference: 9$10 \quad$ July 2015. http://ieeexplore.ieee.org/document/71 75846/ 